\title{
Measures of Interbank Market Structure: An Application to Brazil ${ }^{*}$
}

\author{
Eui Jung Chang** \\ Eduardo José Araújo Lima** \\ Solange M. Guerra \\ Benjamin M. Tabak ${ }^{* * * *}$
}

\begin{abstract}
Many authors emphasize the importance of market structure in the definition of financial fragility; however, a study estimating the degree of completeness and heterogeneity of specific markets is still missing. In this paper, we address this issue. The paper contributes to the contagion literature by proposing measures of completeness and concentration degrees or heterogeneity amongst financial markets. Besides the essentially methodological contribution, we present some empirical results for the Brazilian interbank market.
\end{abstract}

Keywords: Systemic Risk, Financial Contagion, Incomplete Markets, Banking Interconnections, Interbank Market.

JEL Codes: G15, G21.

\footnotetext{
*Submitted in February 2007. Revised in August 2008. The opinions expressed in this paper are those of the authors and do not reflect those of the Central Bank of Brazil. Benjamin M. Tabak gratefully acknowledges financial support from CNPq. The authors thank the comments made by anonymous referees, which helped improve the paper.

${ }^{* *}$ Central Bank of Brazil. E-mail: eui.jung@bcb.gov.br ${ }^{* * *}$ Central Bank of Brazil. E-mail: eduardo.lima@bcb.gov.br **** Central Bank of Brazil. E-mail: solange.guerra@bcb.gov.br ***** Central Bank of Brazil and Universidade Católica de Brasília. E-mails: benjamin.tabak@bcb.gov.br and benjamin@ucb.br
}

Brazilian Review of Econometrics v. $28, \mathrm{n}^{\circ} 2$, pp. $163-189$ November 2008 


\section{Introduction}

Despite the importance of systemic risk assessment, an analytical environment does not yet exist that would make it possible to evaluate the fragility of a financial system and, consequently, establish interbank and payment systems with more stable structures better able to withstand liquidity shocks. Notwithstanding, many researchers have suggested that financial fragility is closely associated with the structure of the interbank market. ${ }^{1}$

Allen and Gale (2000) suggest that a complete market structure in which all banks have connections with each other could result in greater security against unexpected liquidity shocks that affect a specific bank. The purpose of this paper is to contribute to this literature and present some measures of interbank market structure, which can be used to assess how complete and interconnected this market is and also its degree of heterogeneity.

In determining the risk of contagion, the structure of the interbank market and the dimensions of exposures are elements of crucial importance. However, in practical terms, it is quite difficult to determine the precise structure of the interbank market. Very little is known about the topology of bank networks, the dimensions of exposures and the interactions among different types of banks.

The contagion literature has utilized scenario analysis to determine systemic risk. In this approach, it is assumed that each bank in the system enters a situation of default due to some exogenous shock. When a bank is in default, it is unable to honor its commitments to other banks. Such an event can result in contagion, making other banks insolvent and, consequently, generating systemic risk. With this, the spill-over effects of a bank failure on the liquidity and solvency of other banks can be measured.

The basic idea of this literature is that liquidation of long-term assets implies high costs. This way, if a situation of excess demand for liquidity on the part of the public arises, with consequent withdrawals of deposits from a specific bank, that bank will only remain solvent while it is able to meet the demand of each depositor. To meet that demand, banks will normally liquidate short-term assets, such as interbank deposits. The bank is considered technically insolvent when it is forced to liquidate long-term assets in order to meet its client's demand for liquidity. ${ }^{2}$ The implicit hypothesis is that banks possess a preference list for liquidating their assets, known in the literature as the pecking order for asset liquidation. According to this hypothesis, short-term assets are liquidated before anything else, followed by interbank deposits and, finally, long-term assets.

Among the various studies on the subject, Furfine (2003) presents the model

\footnotetext{
${ }^{1}$ Allen and Gale (2000) and Freixas et al. (2000) suggest that the propagation of shocks through the interbank market depends on the precise standard of financial relations among banks.

${ }^{2} \mathrm{~A}$ failure occurs when the bank is unable to meet a demand for liquidity after it has liquidated all of its assets.
} 
for evaluating the risk of financial contagion for the United States. The author utilizes data on bilateral exposures in the interbank market in order to estimate the impact of individual bank bankruptcies on other banks. His results suggest that the systemic risk caused by interconnections in the interbank market is not relevant.

Upper and Worms (2002) evaluate the risks faced by the German interbank market and conclude that, given the profile of interbank credit exposures, there is a possibility of a domino effect on that market. The authors suggest three measures to minimize the risk of contagion. First of all, they encourage banks to act in a more prudent manner. Secondly, should a specific bank become insolvent, procedures should already be in place to guarantee a rapid process of liquidation. Finally, bank exposure should be limited to individual debtors.

Wells (2002) studies the United Kingdom's interbank market while Elsinger et al. (2002) utilize a model of complex networks for interbank market exposures and analyze the consequences of macroeconomic shocks on the Austrian banking system. The Belgian interbank market is analyzed by Degryse and Nguyen (2004), while Blavarg and Nimander (2002) study the Swedish system.

Interestingly, all of these studies agree on the importance attributed to the structure of the interbank market in a definition of financial fragility. The structure of the interbank market and the dimensions of exposures are elements of crucial importance in determining the risk of contagion. More specifically, the degree of completeness and the heterogeneity of the interbank market are closely related to the risk of contagion.

Allen and Gale (2000) present a definition of completeness, while Freixas et al. (2000) discuss characteristics of the market structure associated with the degree of completeness. Although these theoretical characterizations explain the relationship between market structure and financial fragility, they do not give us a way to measure the degree of completeness of a market.

Therefore, this article discusses a few new ideas described in the literature and contributes to the discussion on contagion in financial markets, proposing a measurement of the degree of completeness and the degree of concentration or heterogeneity of the market in question.

As an application of these measures, we will study the Brazilian interbank market. Brazil has an active interbank market, which accounts for approximately $10 \%$ of total banking assets. Thus, it is an important market to study. Notwithstanding, the literature analyzing this market is virtually nonexistent. We try to fill this gap with this paper.

The article is organized as follows. Section 2 presents the concepts of complete and incomplete markets together with some market structures. Section 3 discusses the measurement of concentration and completeness while Section 4 presents specific information regarding Brazil. The conclusions of the article are found in Section 5 . 


\section{Market Structures}

Allen and Gale (2000) modeled the question of financial contagion as a market equilibrium phenomenon ${ }^{3}$ and base their analysis of the risk of propagation of a liquidity shock on two distinct characteristics of the market, called completeness and interconnectedness.

According to the definition put forward by these authors, a complete interbank market is that in which each one of the participating banks has some contractual financial relation with all the other banks in that market or, in a somewhat different sense, each bank is contractually linked directly to each one of the other banks in the system (Figure 1).

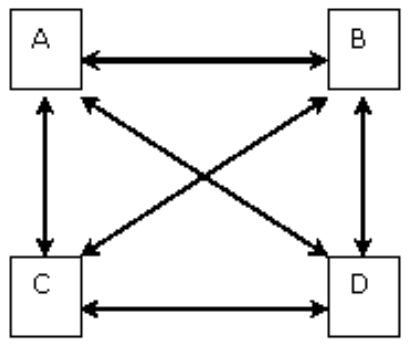

Figure 1

Complete and perfectly connected market structure

In some cases, this structure does not seem to adequately represent reality, considering that the banking sector can be interconnected in a variety of manners, depending, for example, on the existence of transaction costs and information. In order to fully perceive this effect, one should introduce the notion of market incompleteness, assuming that a specific bank will maintain financial relations not with all other banks, but only with some of them. The notion of incomplete markets introduces another concept, that of interconnectedness. In other words, even when all the banks are not directly connected among themselves, they may be linked through indirect connections utilizing different types of networks. In this case, the market is considered incomplete though perfectly interconnected (Figure

\footnotetext{
${ }^{3}$ Allen and Gale (2000) use the notion of region to define the model. According to the authors, region would be a metaphorical way of defining different bank categories. Aside from that, they consider that banks are identical and that their deposits are perfect substitutes.
} 
2). Interconnectedness concerns the dimensions of the credit chains and can be considered a measurement of the extent of the domino effect (Mistrulli, 2005).

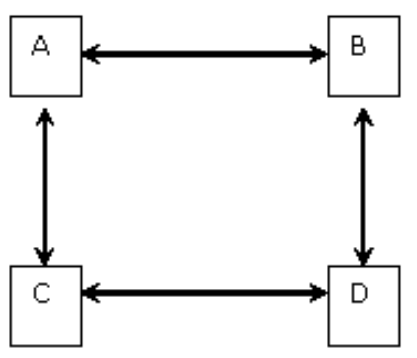

Figure 2

Incomplete and perfectly connected market structure

Therefore, it is only natural to think that various other types of connections exist among institutions in a specific market. An alternative structure can be seen in Figure 3, in which there are two perfect and isolated submarkets.
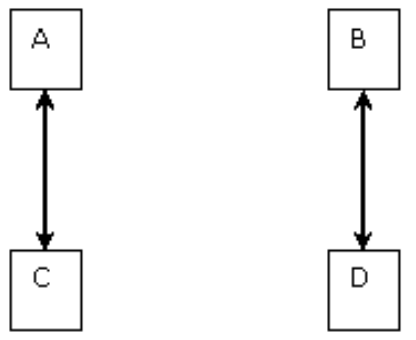

Figure 3

Incomplete and disconnected market structure

Observing these figures, one notes that there is a relation between completeness and interconnection, since if the market is complete, it will necessarily be perfectly interconnected. However, a perfectly interconnected market will not necessarily be complete. 
Given the relations between completeness and the level of interconnection, Allen and Gale (2000) conclude that the propagation of a financial crisis depends vitally on the structure of interconnections among the banks that form the market or, in other words, different interbank market structures will be associated with different magnitudes of risk of financial contagion.

In order to better understand this relation, one can compare the structures represented in Figures 1 and 2 which, while both are perfectly interconnected, differ one from the other in terms of completeness. For a specific interbank market, the more complete the structure, the smaller will be the share of assets of this market held by each bank. In other words, a complete market allows banks to diversify interbank credit risk more than does an incomplete market. Nonetheless, one must underscore that a complete structure does not necessarily mean there will not be risk of contagion, since completeness does not eliminate the possibility of the existence of an endogenous choice of interconnections that could cause contagion. Proceeding with the analysis of the interconnection characteristic, one can state that the risk of contagion will be smaller when the market is less interconnected. The explanation is that, in segmented markets such as that shown in Figure 3, the consequences of a bank failure are restricted to the partition or group in which the failure occurred.

Another important study of interbank relations was authored by Freixas et al. (2000). This study delved into the implications of insolvency of one bank for the stability of the system as a whole, aggregating the too-big-to-fail approach in dealing with structures having banks that operate as "money centers", which is a specific case of an incomplete market structure. One of the justifications for this type of structure would be the economies of scale generated by the efficiency gains obtained by centralizing the liquidity management of the conglomerates involved (Mistrulli, 2005). The result would be less complete structures with greater concentration of assets within the various partitions and increased risk of contagion (Figure 4). However, as the degree of completeness diminishes, the processes of financial reorganization and consolidation tend to reduce market interconnectedness, thus reducing the risk of contagion. This can happen in the case in which financial relations are restricted to the "money centers" and to the other banks of the same partition with no connections among these groups. In this case, the major source of "money center" resources would be outside the interbank market (Figure 5). 


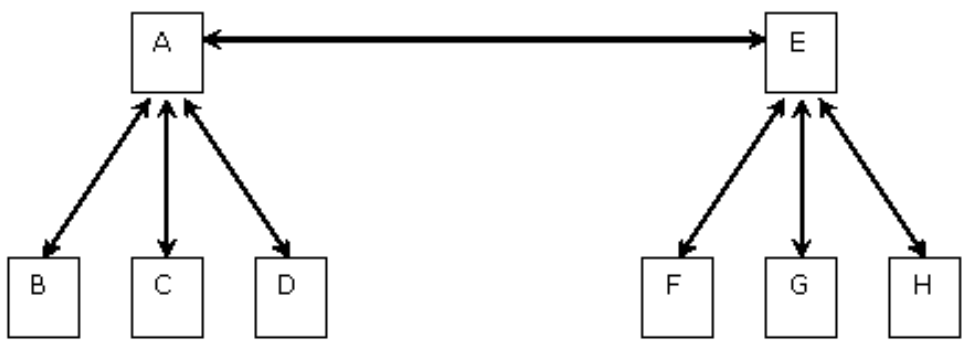

Figure 4

Connected market structure with multiple money centers
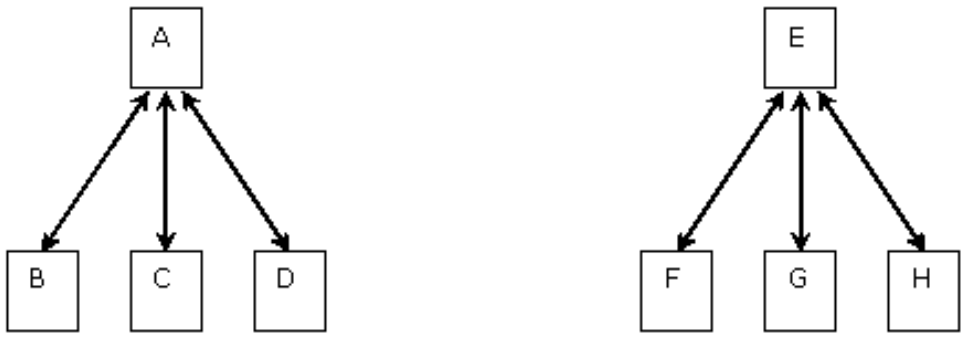

Figure 5

Disconnected market structure with multiple money centers

One of the major conclusions drawn by Freixas et al. (2000) with regard to the connections of the interbank market is that the structure of financial flows affects the stability of the banking system in relation to solvency shocks. On the one hand, interbank connections improve the capacity of the system to withstand situations of insolvency at a specific bank, considering that a share of the losses registered in the portfolio of the insolvent bank is transferred and to some extent diluted with other banks through the relations established on the interbank market. On the 
other hand, this network of connections may allow an insolvent bank to continue operating through the use of the implicit subsidies represented by interbank credit lines, thus weakening incentives for liquidation of inefficient banks.

As a matter of fact, all of these considerations underscore the importance of studying market structure since it is not possible to come to ex-ante knowledge as to how the process of financial consolidation has affected the risk of contagion through the connections that exist on the interbank market.

\section{Measurements of Concentration, Heterogeneity and Completeness of the Interbank Market}

The purpose of this section is to establish the relationship between concentration, heterogeneity, interconnectedness and completeness of the interbank market and to define a measure of completeness.

We start by presenting the Hirschman-Herfindahl index $(H H I)$ and the dual (d) of this index for measuring the concentration of loans and borrowings on the interbank market. After that, we will perform some exercises to gain an insight about the relation between concentration and heterogeneity and the concepts presented by Allen and Gale (2000) and Freixas et al. (2000). In parallel, we will compare the performance of the $H H I$ and its dual.

Finally, a measure of market completeness is defined.

\subsection{The dual of the Hirschman-Herfindahl index}

The $H H I$ is a measurement of concentration frequently used to evaluate the existence of market power in the banking industry. The HHI was used by Nissan (2004) in order to compare the degree of banking concentration in developed and developing countries; Geldos and Roldós (2004) used it in the analysis of the banking structure of emerging countries over the course of time; Rocha (2001) applied it to evaluation of the evolution of banking concentration in Brazil from 1994 to 2000; and Tonooka and Koyama (2003) took advantage of it as the explanatory variable of the relation between interest rates and different credit modalities.

The $H H I$ is obtained by adding together the squares of the proportional shares of each one of the participants in the banking industry analyzed:

$$
H H I=\sum_{i=1}^{n}\left(\frac{x_{i}}{x}\right)^{2}
$$

in which $n$ is the number of banks, $x_{i}$ represents the absolute participation of bank $i$ and $x$ represents the total volume of the banking market analyzed or, in other words, $x=\sum_{i=1}^{n} x_{i}$.

By taking the squares of the relative shares of each bank, one is considering that the larger the institution, the larger its market power. 
The $H H I$ reaches its maximum value equal to 1 in the case of monopolies. On the other hand, when there is perfect competition it will reach its minimum value $1 / n$ which will tend toward zero if the number of banks $n$ is greater.

The U.S. Department of Justice and the Federal Trade Commission utilized the $H H I$ to analyze market concentration, considering that:

- $H H I>0.18$, then the industry is highly concentrated;

- $0.1<H H I<0.18$, then the industry is moderately concentrated;

- $H H I<0.1$, then the industry is not concentrated.

Since the $H H I$ does not directly consider the number of banks, situations may occur in which the $H H I$ does not identify concentration. Furthermore, it is often unclear whether concentration is moderate or strong.

In order to eliminate these problems, the utilization of an $H H I$ dual as a clearer and more objective measurement of banking concentration is proposed, since this dual would provide a percentage of the banks that dominated the market. For a more detailed discussion on the superiority of the dual against the $H H I$, see Chang et al. (2009). In this paper, the authors study the relation between the banking structure and price using a data panel model. The $H H I$ dual is also used by Chang et al. (2008) to measure the banking concentration and to analyze the relation between non-performing loans and factor macroeconomics, systemic risk and banking concentration.

The $H H I$ dual is defined on the basis of a theoretical market that has the same dimensions as the real market, both with regard to the number of participants $n$ and the total volume of the market. However, the theoretical market is stratified into two groups. The first group, with $k$ banks, dominates the entire market and is distributed in equal shares. This means that each bank has a relative participation $p_{M T}$ in the theoretical market. The second group, with $n-k$ banks, has no participation in the market. Thus, the total volume of the theoretical market is equal to the total volume of the real market. Mathematically, $\sum_{i=1}^{n} p_{M T}=$ $\sum_{i=1}^{n} p_{M R_{i}}$ in which $p_{M R}$ is the absolute participation of bank $i$ in the real market. Besides, one considers that the $H H I$ of these two markets are equal $\left(H H I_{M T}=\right.$ $\left.H H I_{M R}\right)$.

This way, the $H H I$ dual is defined as the percentage $d=1-\frac{k}{n}$, which represents the fraction of the banks that do not have participation in the market. Therefore, the concentration of a banking industry measured by the $H H I$ is equivalent to a concentration, also measured by the $H H I$, of the banking industry in which a fraction $1-d$ of the banks controls the entire market.

Since $k$ is a theoretical value that is not known a priori, in order to determine $d$ we establish a mathematical relation between $k$ and the $H H I$ of the real market $H H I_{M R}$, which has a known value. 
Since $k$ banks divide the market equally among themselves and $n-k$ banks do not have participation in the market, we have $p_{M T_{1}}=\ldots=p_{M T_{k}}=p_{M T}$ and $p_{M T_{k+1}}=\ldots=p_{M T_{n}}=0$.

Hence, $H H I_{M T}=\sum_{i=1}^{n}\left(\frac{p_{M T_{i}}}{k \cdot p_{M T}}\right)=\sum_{i=1}^{k}\left(\frac{p_{M T}}{k \cdot p_{M T}}\right)^{2}=k \cdot\left(\frac{1}{k}\right)^{2}=\frac{1}{k}$.

With the assumption that $H H I_{M T}=H H I_{M R}$, then $k=\frac{1}{H H I_{M R}}$.

Therefore, the $H H I$ dual of the real market is $d=1-\frac{1}{n \cdot H H I_{M R}}$.

Consequently, the dual $d$ is an increasing function of the $H H I$ and since $H H I$ varies from $1 / n$ to 1 , the minimum of $d$ is zero, which is the case of perfect competition. When $d$ reaches its maximum, $1-\frac{1}{n}$, we have a monopoly. Note that the maximum of $d$ comes close to 1 when the number of banks is large. Other theoretical details and other applications of the dual can be seen in Souza (1977) and in Souza and Penaloza (2005).

\subsection{The relation between concentration, heterogeneity and complete- ness}

In this study, the objective is to analyze concentration on the interbank market considering the market of lending and borrowing institutions. To do this, one considers the square matrix $E$ of order $n$ representing the matrix of the loans and borrowings, carried out through noninsured operations in the interbank market.

$$
E=\left[\begin{array}{cccc}
0 & e_{12} & \cdots & e_{1 n} \\
e_{21} & 0 & \cdots & e_{2 n} \\
\vdots & \vdots & \ddots & \vdots \\
e_{n 1} & e_{n 2} & \cdots & 0
\end{array}\right]
$$

in which $e_{i j}$ represents the value of the loan from bank $i$ to bank $j$, or from another point of view, the value of the borrowing taken by bank $j$ from bank $i$.

The sum total of line $i, T E L_{i}=\sum_{j=1}^{n} e_{i j}$, with the fixed $i$, provides us with total loans from bank $i$ to the other banks, while the sum total of column $j$, $T E B_{j}=\sum_{i=1}^{n} e_{i j}$, with fixed $j$, gives us total borrowings of bank $j$. Thus, we come to the overall total of loans, which is $T E=\sum_{i=1}^{n} T E L_{i}=\sum_{j=1}^{n} T E B_{j}$.

In order to analyze the behavior of $H H I$ and $d$, several situations will be considered, from a market with perfect competition to an extremely concentrated market. To simplify the analysis, the market will be divided into two groups, just as defined in the HHI dual. The first group, with $r$ banks, holds the entire market with equal participation among the different institutions, and the second one has no participation in the interbank market. At the same time, the market is considered to have the same number $r$ of lending and borrowing banks and that 
all loans/borrowings $e$ have the same value of 100 units. With these assumptions, matrix $E$ is symmetric and, therefore, the structures of the loans and borrowings are identical. Thus, analyzing the concentration of the loans will suffice.

Case 1 - Perfect competition - the number of banks $k$ that dominate the market is equal to the total number of banks $n$, that is, $n=r=100$. In this case, we have $T E L_{i}=T E B_{i}=9,900$, for all $i, j=1, \ldots, 100$ and $T E=990,000$. This situation is presented in Table 1 .

From the point of view of the concepts of completeness and interconnectedness established by Allen and Gale (2000), this market structure is complete and perfectly interconnected.

Concentration of the loans for each bank $i$, individually, measured by the HHI is $H H I_{i}=\sum_{j=1}^{99}\left(\frac{100}{9900}\right)^{2}=0.01$, and $d_{i}=1-\frac{1}{99 . H H I_{i}}=0$ viewed through the HHI dual.

Note that, although we have 100 banks in this market, we must consider $n=99$ in order to calculate the $H H I$ and the $d$ of the banks individually, considering that a bank does not lend to itself.

Since $H H I=0.01$ for all banks, we conclude that the means of the $H H I_{i}$ and of the $d_{i}$ are respectively:

$$
m_{-} H H I=\sum_{i=1}^{100} \frac{H H I_{i}}{100}=H H I_{i}=0.01 \quad \text { and } \quad m_{-} d=\sum_{i=1}^{100} \frac{d_{i}}{100}=d_{i}=0
$$

Since the market is homogeneous, the means of $H H I_{i}$ and $d_{i}$, weighted by the relative proportion of the loans, are equal to the simple means. So, wm_HHI= 0.01 and $w m_{-} d=0$.

The $H H I$ and the dual of the total loans are

$$
H H I_{T E}=\sum_{i=1}^{100}\left(\frac{9900}{990000}\right)^{2}=0.01 \quad \text { and } \quad d_{T E}=0
$$

Note that, in the case of $n=k$, the measurements of $H H I$ concentration and $d$ are consistent, whether one considers the banks individually or the market as a whole. All of these measurements detect the perfect competition.

Case 2 - the interbank market is concentrated in the hands of 50 banks which divide the market among themselves in a homogeneous manner. Therefore, $n=$ $100, k=50, T E L_{i}=T E B_{j}=4.900$ for $i, j=1, \ldots, 50$ and $T E L_{i}=T E B_{j}=0$ for $i, j=51, \ldots, 100$ and $T E=245,000$. Table 2 presents this situation.

In this case, following the definition provided by Allen and Gale (2000), we conclude that the market structure is incomplete and disconnected. 


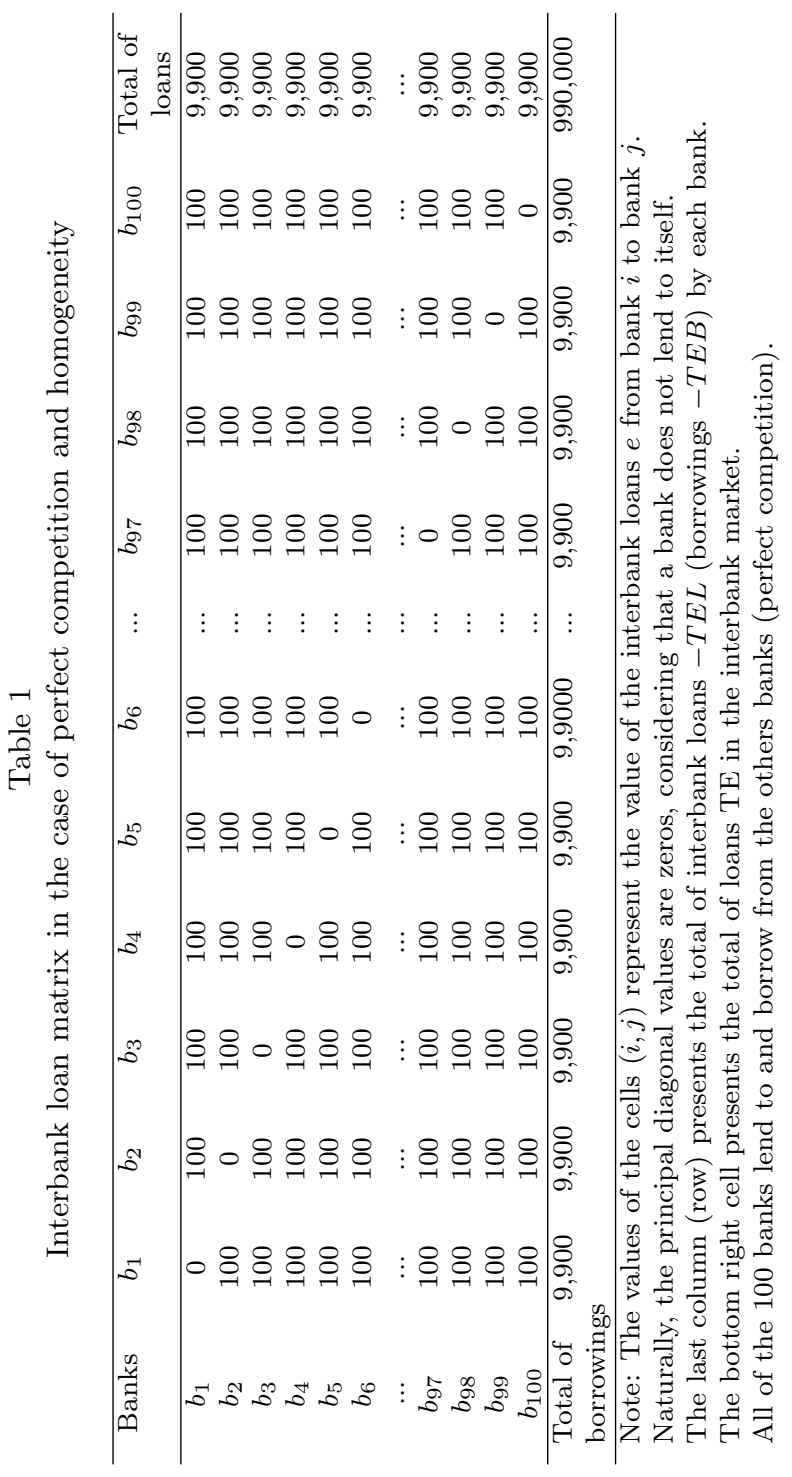




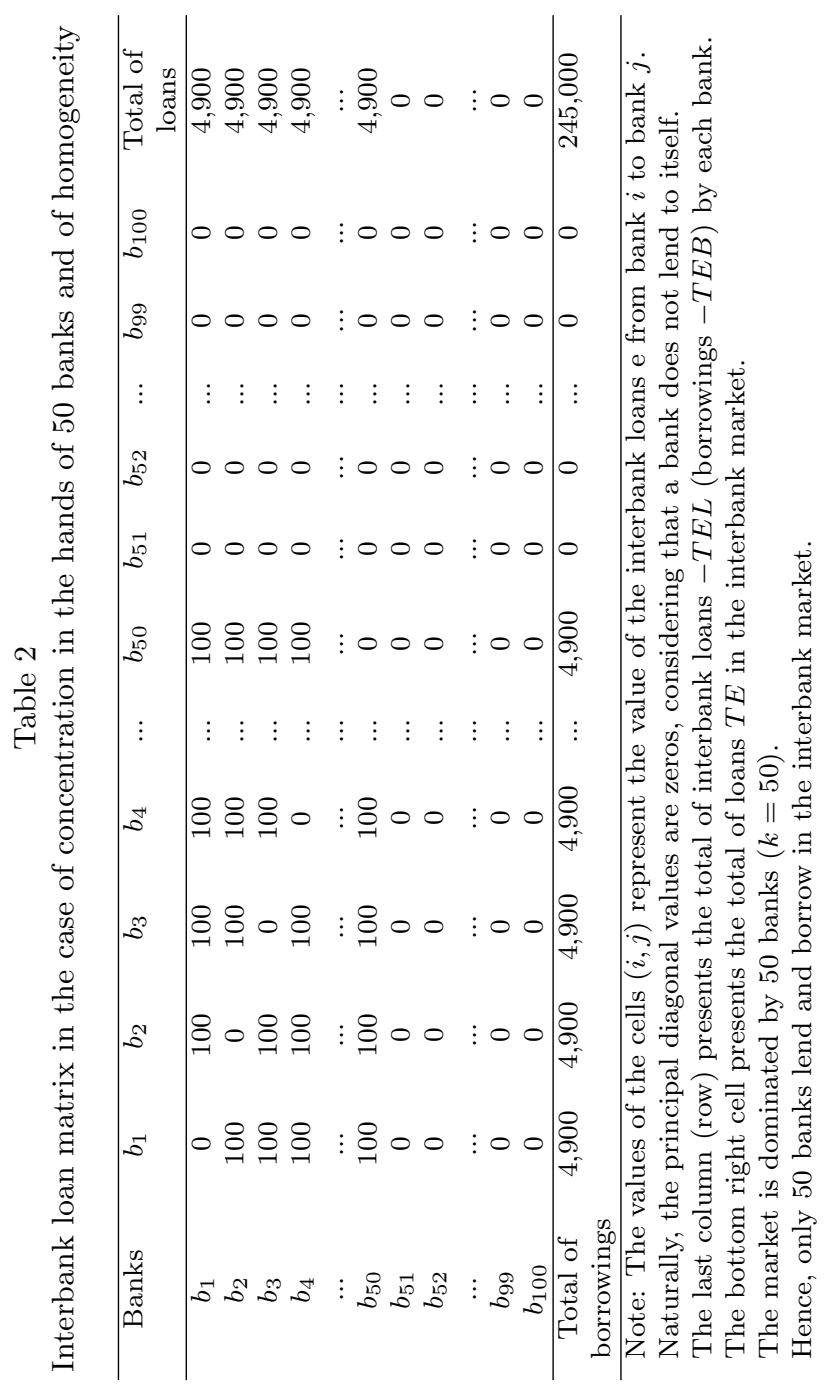


The indices of concentration of the loans by each bank $i$ participating in the first group - those that dominate the market - will be

$H H I_{1 i}=\sum_{\substack{j=1 \\ j \neq 1}}^{50}\left(\frac{100}{4900}\right)^{2}+\sum_{j=51}^{100}\left(\frac{0}{4900}\right)=0.0204$ and $d_{1_{i}}=1-\frac{1}{99 . H H I_{1_{i}}}=0.5051$

For the banks in the second group - those with no participation in the market - it was decided that $H H I_{2 i}=0$ and $d_{2 i}=0$. Consequently, in this case, we conclude that the means of $H H I_{i}$ and of $d_{i}$ are respectively:

$$
\begin{aligned}
m_{-} H H I & =\sum_{i=1}^{50} \frac{H H I_{1 i}}{100}+\sum_{i=51}^{100} \frac{H H I_{2 i}}{100}=\frac{50}{100} H H I_{1 i}=0.0102 \\
m_{-} d & =\sum_{i=1}^{50} \frac{d_{1 i}}{100}+\sum_{i=51}^{100} \frac{d_{2 i}}{100}=\frac{50}{100} d_{1 i}=0.0204
\end{aligned}
$$

While the weighted means of the $H H I_{i}$ and of $d_{i}$ viewed in terms of market participation, respectively, are as follows:

$$
\begin{aligned}
w m_{-} H H I & =\frac{1}{245000}\left(\sum_{i=1}^{50} 4900 . H H I_{1 i}+\sum_{i=51}^{100} 0 . H H I_{2 i}\right)=0.0204 \quad \text { and } \\
w m_{-} d & =\frac{1}{245000}\left(\sum_{i=1}^{50} 4900 . d_{1 i}+\sum_{i=51}^{100} 0 . d_{2 i}\right)=d_{1 i}=0.5051
\end{aligned}
$$

Note that, differently from case 1 , the simple arithmetic mean of both the $H H I$ and the dual proved to be inadequate. However, the weighted mean of the dual shows us that $50.51 \%$ of the banks control the market, quite close to the assumed hypothesis in this exercise that $50 \%$ of the banks dominate the market.

The HHI of the total loans in this case is $H H I_{T E}=\sum_{i=1}^{50}\left(\frac{4900}{245000}\right)^{2}=0.02$, while the dual is $d_{T E}=0.50$.

Table 3 presents the results of cases 1 and 2 and other cases with high concentration. According to Allen and Gale's concepts of completeness and interconnectedness, as already stated, case 1 represents a complete and a perfectly interconnected market structure. In all of the other cases, the market structure is incomplete and disconnected.

It is possible to note that the consistency that exists between $H H I$ and $d$ in the case of perfect competition is not maintained once a certain degree of concentration is surpassed. 
Table 3

Concentration indices in the homogeneity cases

\begin{tabular}{|c|c|c|c|c|c|c|c|c|}
\hline \multirow[t]{3}{*}{$k$} & \multicolumn{4}{|c|}{$I H H$} & \multicolumn{4}{|c|}{$d$} \\
\hline & \multicolumn{4}{|c|}{ Weighted } & \multicolumn{4}{|c|}{ Weighted } \\
\hline & Bank & Mean & Mean & Total loans & Bank & Mean & Mean & Total loans \\
\hline 100 & 0.0101 & 0.0101 & 0.0101 & 0.0100 & 0.0000 & 0.0000 & 0.0000 & 0.0000 \\
\hline 50 & 0.0204 & 0.0102 & 0.0204 & 0.0200 & 0.5051 & 0.2525 & 0.5051 & 0.5000 \\
\hline 20 & 0.0526 & 0.0105 & 0.0526 & 0.0500 & 0.8081 & 0.1616 & 0.8081 & 0.8000 \\
\hline 15 & 0.0714 & 0.0107 & 0.0714 & 0.0667 & 0.8586 & 0.1288 & 0.8586 & 0.8500 \\
\hline 12 & 0.0909 & 0.0109 & 0.0909 & 0.0833 & 0.8889 & 0.1067 & 0.8889 & 0.8800 \\
\hline 10 & 0.1111 & 0.0111 & 0.1111 & 0.1000 & 0.9091 & 0.0909 & 0.9091 & 0.9000 \\
\hline 5 & 0.2500 & 0.0125 & 0.2500 & 0.2000 & 0.9596 & 0.0480 & 0.9596 & 0.9500 \\
\hline 3 & 0.5000 & 0.0150 & 0.5000 & 0.3333 & 0.9798 & 0.0294 & 0.9798 & 0.9700 \\
\hline \multicolumn{9}{|c|}{$\begin{array}{l}\text { Note: This table presents the concentration indices } H H I \text { and } d \text { of each bank individually, } \\
\text { the mean and the weighted mean of these indices, and the concentration indices for the total } \\
\text { loans of each bank. The interbank market has } 100 \text { banks, and all of the loans have the same } \\
\text { value. } k \text { is the number of banks that dominate the market. } \\
\text { Hence, each row of the table presents the concentration indices of a different market structure, } \\
\text { from the perfect competition }(k=100) \text { to a market that is highly concentrated }(k=3) \text {. }\end{array}$} \\
\hline
\end{tabular}

Comparing the HHI with the dual, one notes that the HHI may indicate that there is no concentration for the cases in which the market is concentrated, while the dual permits observation not only of the aspect of the existence of concentration, but also of the degree of that concentration. Let us look at the case in which 12 banks dominate the market $(k=12)$. The $H H I$ of each bank is 0.0909 , while the $H H I$ of total loans is 0.0833 . Based on the parameters defined by the United States in its antitrust legislation, ${ }^{4}$ this market is considered not concentrated. However, the HHI dual indicates that the market is concentrated. According to the dual of each bank, the market is concentrated in the hands of $11.11 \%$ of the banks and according to the dual of total loans, in the hands of $12 \%$ of the banks.

Furthermore, it is important to emphasize that, in Table 3, the simple arithmetic means of the $H H I$ and of $d$ show deterioration in their capacity to indicate concentration as the market becomes more concentrated, while the weighted means remain quite close to the concentration indices of the loans. Note also that the weighted mean is equal to the concentration indices of the bank. These results are not coincidental. As shown in the Appendix, this fact will always occur if we accept the assumptions considered in this study.

In the cases analyzed so far, concentration is homogeneous. Let us analyze the behavior of the concentration indices in the case of heterogeneity. To do this, one considers the banking system with $n=100$ banks, in which 50 banks dominate the market, as follows: 10 banks hold $60 \%$ of the market, 10 banks hold $20 \%$ of the market and 30 banks hold $20 \%$ of the market. This market division is considered both for the market of lending institutions and for that of borrowing institutions. Thus, one arrives at symmetry in the interbank matrix. Table 4 presents the

\footnotetext{
${ }^{4}$ U.S. Department of Justice and the Federal Trade Comission (1997) "Horizontal Merger Guidelines", Section 1.5.
} 
loan/borrowing matrix for this case of heterogeneity.

Observe that, in the case of heterogeneity, the banking structure is incomplete and is closer to the concept of "money centers" as defined by Freixas et al. (2000).

Note that, in Table 5, the results obtained for the concentration indices in the case of homogeneity are maintained in the case of heterogeneity. Based on the parameters established by the United States antitrust legislation, the HHI does not perceive market concentration, not even when the analysis is carried out for the banks on an individual basis. Observe that the HHI of the 10 banks with $60 \%$ of the market is equal to 0.1111 , indicating moderate concentration, while the HHI dual shows that $9.09 \%$ of the banks control the market. The HHI of total loans is 0.0413 , indicating that the market is not concentrated. However, the dual aggregates more information, indicating that the market is concentrated in the hands of $24.18 \%$ of the banks.

The exercises performed confirm that the $H H I$ dual can be considered a measurement of concentration superior to the HHI. Therefore, $d$ will be used to measure the degree of heterogeneity in the distribution of loans and borrowings in the Brazilian interbank market. Second, the mean is not the most adequate measure to assess the concentration of the interbank market as a whole.

In relation to the concepts of concentration, heterogeneity, completeness and interconnectedness, we saw that in the situation where there is perfect homogeneity, such as in case 1, the interbank market structure is not concentrated, is perfectly interconnected, and therefore, complete in the sense of Allen and Gale (2000).

From this extreme case to the case where there is heterogeneity, we have that the higher the heterogeneity, the higher the concentration. This point can be seen by comparing the case of homogeneity for $k=50$ (Table 3 ) and the case of heterogeneity. In both, 50 banks dominated the market, but the concentration is higher in the heterogeneity case. This is because the higher the heterogeneity, the higher the relative participation of some banks and, consequently, the higher the concentration. A demonstration is provided in the Appendix. 


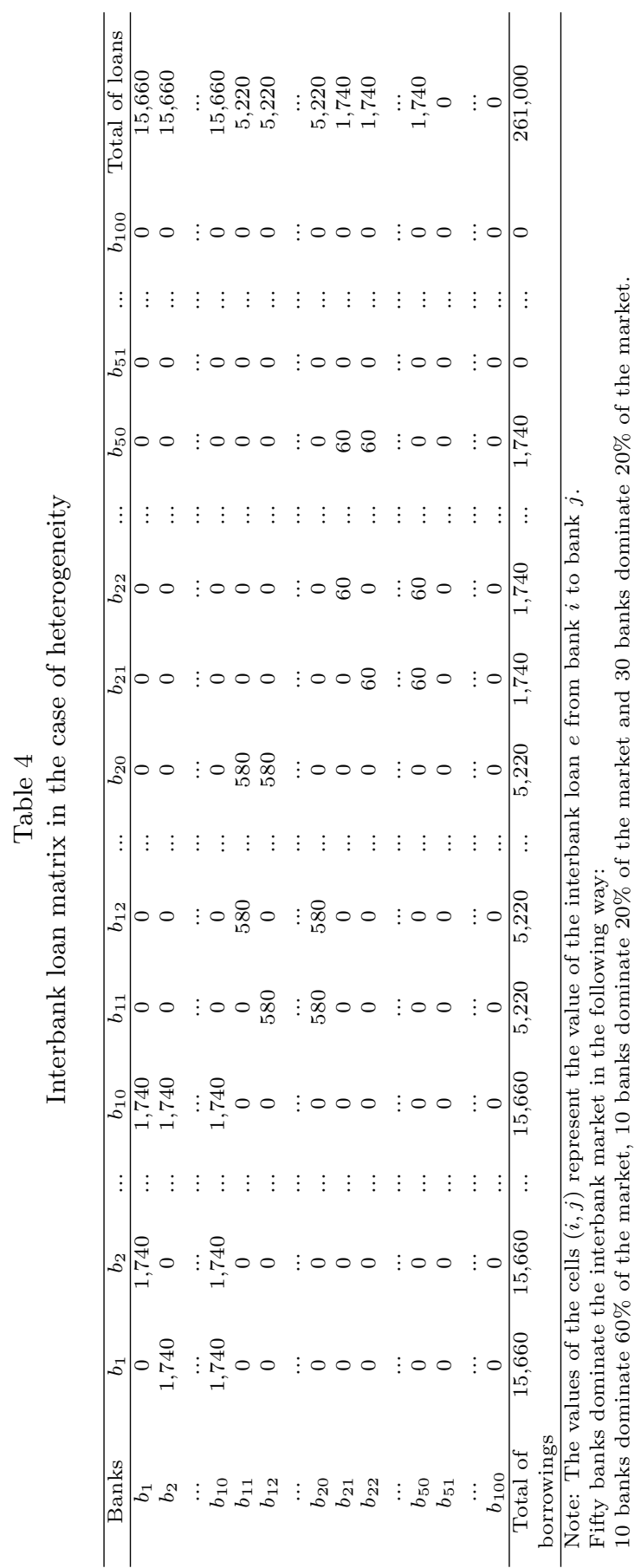


Table 5

Concentration indices in the heterogeneity case

\begin{tabular}{llc}
\hline \multicolumn{1}{c}{ Itemization } & $H H I$ & $d$ \\
\hline 10 banks with $60 \%$ of the market & 0.1111 & 0.9091 \\
10 banks with $20 \%$ of the market & 0.1111 & 0.9091 \\
30 banks with 20\% of the market & 0.0345 & 0.7071 \\
Mean & 0.0326 & 0.3939 \\
Weighted mean & 0.0958 & 0.8687 \\
Total of loans (borrowings) & 0.0413 & 0.7581 \\
\hline Note: This table presents the concentration indices $H H I$ and $d$ of \\
each bank individually, the mean and the weighted mean of these indices, \\
in the case of heterogeneous concentration. Fifty banks dominate the \\
interbank market in the following way: 10 banks hold $60 \%$ of the market, \\
10 banks hold 20\% of the market and 30 banks hold 20\% of the market. \\
It also presents the concentration indices of total loans, which are \\
equal to the concentration indices of the total borrowings because of \\
market symmetry.
\end{tabular}

Still confronting these cases, according to Freixas et al. (2000), the risk that contagion could spread to the whole system is greater in the case of homogeneity, because it has only one "money center", while the case of heterogeneity is disconnected with three "money centers". So, to assess the risk of contagion, in addition to measuring the degree of concentration, it is essential to measure the degree of interconnectedness or completeness of the market.

\subsection{Measurement of completeness}

An $H H I$ dual equal to 0 represents a complete market in which all banks are interconnected among themselves. Another way of measuring the degree of completeness of a banking structure consists in simply counting the proportion of interconnections in that system. For example, if there are $n$ banks, a market is considered complete when, and only when, these $n$ are interconnected with other $n-1$ banks.

Taking a matrix $E$ of loans/borrowings in the interbank market, the number of interconnections will be given by the number of cells with a non-zero entry. Since a bank does not lend to itself, the maximum number of interconnections will be $n(n-1)$, which represents a complete market. This way, we define the degree of completeness of the market by:

$$
C=\frac{1}{n(n-1)} \sum_{i=1}^{n} \sum_{\substack{j=1 \\ i \neq j}}^{n} 1_{i, j}
$$

in which $1_{i, j}$ is an indicator function showing that

$$
1_{i, j}= \begin{cases}1, & \text { if there exists an interconnection between } i \text { and } j \\ 0, & \text { otherwise }\end{cases}
$$


This measurement is consistent with the definition put forward by Allen and Gale (2000). In their opinion, the complete interbank market is that in which each one of the participating banks maintains some financial contractual relations with all of the other banks in that market or, somewhat differently, each bank $i$ is directly connected to each one of the other $j$ banks in the system.

\section{Empirical Results}

In this section, we present the empirical results for Brazilian interbank market data. The interbank market accounts for approximately $10 \%$ of banking assets, and it is therefore an important market. Data for the first business day of the second half of 2004 were utilized. The period under analysis was chosen due to data availability. Only data on interbank market among conglomerates without collateral or guarantees were utilized. We included all banks that perform operations in this market (total of 109 banks). It should be underscored that other days in the second half of 2004, the first and the last business days of 2004, were also utilized and that the qualitative results were the same. The dataset comes from the Central Bank of Brazil.

The measurement $C$ of market completeness is less than 0.02 , suggesting that the Brazilian interbank market is not complete. This result is not new and is consistent with the studies carried out for other countries, such as the study performed by Boss et al. (2004) for Austria. Given that the market structure is incomplete, the degrees of concentration of the loans and borrowings from all financial system institutions were analyzed.

The HHI dual of concentration was calculated for the lending and borrowing institutions. Table 6 presents the descriptive statistics for the dual of lending and borrowing institutions. As is evident, the medians are quite high, indicating that this market is extremely concentrated. The data do not follow the normal distribution.

Table 6

Descriptive statistics for the concentration index (dual)

\begin{tabular}{lcc}
\hline \multicolumn{1}{c}{ Itemization } & Dual for lenders & Dual for borrowers \\
\hline Mean & 0.9813 & 0.9866 \\
Median & 0.9876 & 0.9918 \\
Maximum & 0.9945 & 0.9945 \\
Minimum & 0.9097 & 0.9215 \\
Standard deviation & 0.0165 & 0.0130 \\
Skewness & -1.79 & -2.47 \\
Kurtosis & 6.63 & 9.49 \\
& & \\
Jarque-Bera & 111.37 & 412.38 \\
$p$-value & 0.00 & 0.00 \\
\hline
\end{tabular}


We may suppose that the median of the lending institutions is below that of the borrowing institutions, meaning that the lending institutions are seeking to diversify loans in the interbank market. This hypothesis is tested through a median equality test and we can see in Table 7 that the null hypothesis of equal medians is strongly rejected, independently of the test utilized.

Table 7

Equality test of medians for the concentration index (dual)

\begin{tabular}{lccc}
\hline \multicolumn{1}{c}{ Method } & d.f. & Value & $p$-value \\
\hline Wilcoxon/Mann-Whitney & - & 3.0202 & 0.0025 \\
Wilcoxon/Mann-Whitney(tie-adj) & - & 3.0717 & 0.0021 \\
Med. Chi-square & 1 & 7.2413 & 0.0071 \\
Adj. Med. Chi-square & 1 & 6.5681 & 0.0104 \\
Kruskal-Wallis & 1 & 9.1272 & 0.0025 \\
Kruskal-Wallis (tie-adj) & 1 & 9.4406 & 0.0021 \\
Van der Waerden & 1 & 9.7872 & 0.0018 \\
\hline
\end{tabular}

In what follows, we present the kernel densities for the duals of the lending and borrowing institutions. In line with the results obtained in Table 7, one can easily perceive that the mass of probability in smaller duals is greater for the lending institutions than for the borrowing ones, indicating some degree of corroboration of the hypothesis of diversification.

Figure 6

Kernel Densty(Epanectritov, $h=0.0051)$

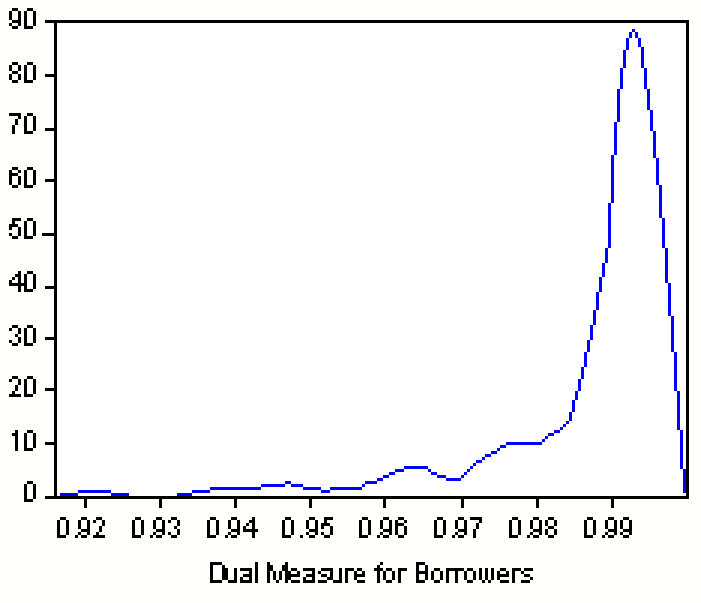


Figure 7

Kemel Dersity(Ep anechnikov, $\mathrm{h}=0.0129)$

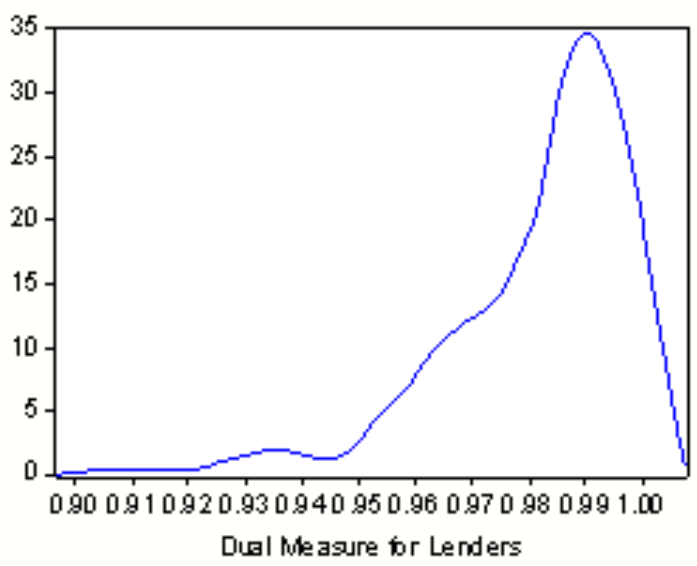

The distribution of the duals of the banks that operate on the interbank market as presented in Table 6 suggests that, differently from the market structure presented in Allen and Gale (2000), the connections in this market are highly heterogeneous. The fact of the matter is that the results suggest a market structure closer to a "money center" as proposed in Freixas et al. (2000).

Since the dual of the lending and borrowing institutions is quite high, concentration is high. Consequently, the number of relevant interconnections is rather low. These results suggest that systemic risk originating in the interbank system is low. Here, we are considering only part of the interbank relations that can, for example, encompass derivatives. Thus, this exercise must be seen as a first approximation for studying the interbank market.

The implications of these results are that regulators should follow the interbank market closely as concentration/heterogeneity within this market could imply contagion risk.

\section{Final Considerations}

This article introduces some ideas on how to measure concentration in the interbank market and the degree of heterogeneity in the loans and borrowings of this market. The measurements suggested in the article are extremely important for characterizing the degree of concentration in this market and may be utilized as measurements of financial fragility.

Utilization of measurements of concentration in the Brazilian interbank market suggests that this market is not characterized by financial fragility and does not 
currently represent a factor of systemic risk. This conclusion can be drawn from a reading of the high concentration indices found for the interbank system. The $H H I$ duals for lending and borrowing institutions are approximately 0.987 and 0.992, respectively. This suggests that the interbank market has few interconnections.

Dynamic measurements accompanying the evolution of this market and the degree of completeness and heterogeneity are important and are essential tools that can aid in modeling Brazilian financial markets.

It is worth stressing that the analysis focuses only on the interbank deposit market without analyzing the interbank exchange market, for example. Consequently, the results found are an approximation and must be evaluated with caution.

Various questions still remain on the agenda. The definition of market completeness can be improved. Also, the analysis of the matrix of interbank market, distinguishing lending institutions from net borrowing institutions can be studied further. Moreover, loans and borrowings are highly heterogeneous and it is essential that one seek out heterogeneity measurements of the interconnections that exist in this system.

\section{References}

Allen, F. \& Gale, D. (2000). Financial contagion. The Journal of Political Economy, 108(1):1-33.

Blavarg, M. \& Nimander, P. (2002). Interbank exposures and systemic risk. Sveriges riskbank. Economic Review, 2:19-45.

Boss, M., Elsinger, H., Summer, M., \& Thurner, S. (2004). Network topology of the interbank market. Quantitative Finance, 4(6):677-684.

Chang, E. J., Guerra, S. M., Lima, E. J. A., \& Tabak, B. M. (2008). The stabilityconcentration relationship in the Brazilian banking system. Journal of International Markets, Institutions and Money, 18(4):388-397.

Chang, E. J., Guerra, S. M., Penaloza, R. A. S., \& Tabak, B. M. (2009). Measuring banking concentration: The Brazilian case. International Journal of Accounting and Finance, forthcoming.

Degryse, H. \& Nguyen, G. (2004). Interbank exposures: An empirical examination of systemic risk in the Belgian banking system. Nationale Bank van Belgie, Working Paper 43.

Elsinger, J., Lehar, A., \& Summer, M. (2002). Risk assessment for banking systems. Oesterreichische Nationalbank, Working Paper 79. 
Freixas, S., Parigi, B. M., \& Rochet, J. C. (2000). Systemic risk, interbank relations and liquidity provision by the Central Bank. Journal of Money, Credit and Banking, 32(3):611-638.

Furfine, C. H. (2003). Interbank exposures: Quantifying the risk of contagion. Journal of Money, Credit and Banking, 35(1):111-128.

Geldos, R. G. \& Roldós, J. (2004). Consolidation and market structure in emerging market banking systems. Emerging Markets Review, 5:39-59.

Mistrulli, P. E. (2005). Interbank lending patterns and financial contagion. Banca d'Italia, mimeo 29.

Nissan, E. (2004). Comparing bank concentration across developing and developed countries. Journal of Global Business, 15(28):15-24.

Rocha, F. A. S. (2001). Evolução da concentração bancária no Brasil (1994-2000). Central Bank of Brazil, Technical Notes 11.

Souza, J. (1977). Estatística Econômica e Social. Campus, São Paulo.

Souza, J. \& Penaloza, R. S. (2005). Estatística exploratória. UnB Department of Economics, mimeo.

Tonooka, E. K. \& Koyama, S. M. (2003). Taxa de juros e concentração bancária no Brasil. Central Bank of Brazil, Working Paper Series 62.

Upper, C. \& Worms, W. (2002). Estimating bilateral exposures in the German interbank market: Is there a danger of contagion? Deutsche Bundesbank, Economic Research Centre, Discussion Paper 9.2.

U.S. (1997). Department of Justice and the Federal Trade Comission. Horizontal Merger Guidelines, section 1.5.

Wells, S. (2002). UK interbank exposures: Systemic risk implications. Financial Stability Review, December. Bank of England. 


\section{Appendix}

\section{Demonstrations for the Case of Homogeneity}

An analysis is made of a market with $n$ banks, divided into two groups: the first group, with $r$, controls the entire market with participation equally distributed across the banks, while the second group, with $n-r$ banks, has no participation in the interbank market. It is also considered that the market has the same number $r$ of lending and borrowing banks and that all loans and borrowings $e$ have the same value.

$$
E=\left[\begin{array}{ccccccc}
0 & e & \cdots & e & 0 & \cdots & 0 \\
e & 0 & \cdots & e & 0 & \cdots & 0 \\
\vdots & \vdots & \ddots & \vdots & \vdots & \cdots & \vdots \\
e & e & \cdots & 0_{r \times r} & 0 & \cdots & 0 \\
0 & 0 & \cdots & 0 & 0 & \cdots & 0 \\
\vdots & \vdots & \vdots & \vdots & \vdots & \cdots & \vdots \\
0 & 0 & \cdots & 0 & 0 & \cdots & 0
\end{array}\right]_{n \times n}
$$

The sum total of line $i, T E L_{i}=\sum_{j=1}^{n} e_{i j}$ with fixed $i$, provides us with total loans from bank $i$ to the other banks, while the sum total of column $j, T E B_{j}=$ $\sum_{i=1}^{n} e_{i j}$ with fixed $j$, gives us the total borrowings of bank $j$. Thus, we have the overall total of loans, which is $T E=\sum_{i=1}^{n} T E L_{i}=\sum_{j=1}^{n} T E B_{j}$.

With these assumptions, matrix $E$ is symmetrical and, therefore, the structures of loans and borrowings are identical. Thus, analyzing the concentration of loans is enough.

- $H H I$ and $d$ of each bank:

For the group of banks that control the market, we have:

$$
\begin{aligned}
H H I_{1 i} & =\sum_{i=1}^{r-1}\left(\frac{T E L / r-1}{T E L}\right)^{2}=(r-1)\left(\frac{1}{r-1}\right)^{2}=\frac{1}{r-1} \\
d_{1 i} & =1-\frac{1}{(n-1) \cdot H H I_{i}}=1-\frac{r-1}{n-1}=\frac{n-r}{n-1}
\end{aligned}
$$

It was determined that the concentration indices for the group that does not have participation in the market are $H H I_{2 i}=0$ and $d_{2 i}=0$.

While the $H H I$ always provides the same value independently of the number $n$ of banks on the market, the $H H I$ dual considers the increase or reduction 
in the number $n$ of the banks on the market, establishing the percentage of banks that do not participate in the market.

Note that the $H H I$ and $d$ values do not depend on the value of the loans $e$. However, to obtain this result for the $H H I$ and the $d$, it is essential that all loans have the same value $e=\frac{T E L}{r-1}$, considering the fact that the banks dominating the market are equally divided among themselves.

- Simple arithmetic mean of $H H I$ and $d$ :

$$
\begin{aligned}
m_{-} H H I & =\frac{1}{n}\left(\sum_{i=1}^{r} H H I_{1 i}+\sum_{i=r+1}^{n} H H I_{2 i}\right)=\frac{r}{n} \frac{1}{(r-1} \\
m_{-} d & =\frac{1}{n}\left(\sum_{i=1}^{r} d_{1 i}+\sum_{i=r+1}^{n} d_{2 i}\right)=\frac{r}{n} \frac{(n-r)}{(n-1)}
\end{aligned}
$$

Note that the arithmetic mean is nothing more than a percentage of the $H H I$ and of the $d$ of the banks individually. Thus, to the extent in which the market becomes more concentrated (a smaller $r$ ), this percentage diminishes. This fact demonstrates the deterioration in average capacity to measure the concentration of total loans detected in Table 3.

- Weighted arithmetic means of $H H I$ and $d$ :

$$
\begin{aligned}
w m_{-} H H O & =\sum_{i=1}^{r} \frac{T E L_{i}}{T E} H H I_{1 i}=\sum_{i=1}^{r} \frac{T E L_{i}}{r \cdot T E L_{i}} \frac{1}{r-1}=\frac{1}{r-1}=H H I_{1 i} \\
w m_{-} d & =\sum_{i=1}^{r} \frac{T E L_{i}}{T E} d_{1 i}=\sum_{i=1}^{r} \frac{T E L_{i}}{r \cdot T E L_{i}} \frac{n-r}{n-1}=\frac{n-r}{n-1}=d_{1 i}
\end{aligned}
$$

The weighted means of the $H H I$ and $d$ are equal to the $H H I$ and $d$ concentration indices of the banks controlling the market. This fact is heuristically identified in Table 3 .

- $H H I$ and $d$ of the total loans:

Since all loans $e$ have the same value in all the $r$ banks controlling the market loans among themselves, we conclude $T E L_{1}=\ldots=T E L_{r}=T E L$ and $T E L_{r+1}=\ldots=T E L_{n}=0$. 
Thus,

$$
\begin{aligned}
H H I_{T E} & =\sum_{i=1}^{n}\left(\frac{T E L_{i}}{T E}\right)^{2}=\sum_{i=1}^{r}\left(\frac{T E L}{r \cdot T E L_{i}}\right)^{2}=\frac{1}{r} \\
d_{T E} & =1-\frac{1}{n \cdot H H I_{T E}}=1-\frac{r}{n}=\frac{n-r}{n}
\end{aligned}
$$

Observe that the weighted means are a good approximation for the $H H I$ and $d$ of total loans. Once again, the HHI does not consider the dimensions of the market. One can also observe that the $H H I$ and the $d$ do not depend on the value of the loans $e$. However, it is essential that all loans have the same value and that all the dominant banks divide the market equally among themselves.

\section{Demonstration of the Relation between Concentration and Heterogene- ity}

First of all, we will calculate the weighted mean of the $H H I$ dual. To do that, we will consider a market with $n$ banks, divided into $x$ groups, each one with $n_{1}, \ldots, n_{x}$ banks. These groups are disconnected from each other. It is also considered that the market has the same number of lending and borrowing banks.

As the groups are disconnected, the dual $d_{j}$ for the banks of the group $j, j=$ $1, \ldots x$, is $d_{j}=\frac{n-n_{j}}{n-1}$.

Considering the overall total of loans $T E$ and the proportion of $T E$ that the group $j$ holds (denoted by $p_{j}$ ), the dual weighted mean is:

$$
w m_{x}=\frac{1}{T E}\left[\sum_{j=1}^{N_{j}} \frac{p_{1} T E}{n_{1}} d_{1}+\cdots+\sum_{j=1}^{n_{x}} \frac{p_{x} T E}{n_{x}} d_{x}\right]=p_{1} d_{1}+\cdots+p_{x} d_{x}
$$

Now, we will consider two banking systems, both of them with $n$ banks, but one is divided into $y$ groups, while the other one is divided into $z$ groups, with $y>z$. So, the former banking system is more heterogeneous than the latter one.

We will show that higher heterogeneity implies higher concentration when all groups of a banking system have the same number of banks. So, for the former system we have, $n_{1}=\ldots=n_{y}=\frac{n}{y}$ and for the latter one, $\bar{n}_{1}=\ldots=\bar{n}_{y}=\frac{n}{z}$. Consequently, the duals are the same, too $d_{1}=\ldots=d_{y}$ and $\bar{d}_{1}=\ldots=\bar{d}_{y}$. Since $p_{1}+\ldots+p_{x}=1$, the concentration indices for each banking system, measured by the dual weighted mean, are $w m_{y}=d_{1}=\frac{n-n / y}{n-1}=\frac{n(y-1)}{y(n-1)}$ and $\bar{d}_{1}=\frac{n-/ z}{n-1}=$ $\frac{n(z-1)}{z(n-1)}$.

As $y>z$, then $w m_{y}>w m_{z}$. Hence, the former banking system is more concentrated than the latter one. 
Note that $z=1$, which means that the latter banking system is homogeneous. Therefore, we also showed that heterogeneous banking systems are more concentrated than homogeneous ones. 